Original Article

\title{
Correlation between High Heel Vs Flat Footwear with Balance and Foot Pain in Physiotherapy Students
}

\author{
V.Rajalaxmi, S. Lakshmi, K. Kamatchi, C.J. Jayson, Devika E
}

ABSTRACT

OBJECTIVE: To find out the correlation of habitual footwear with balance and foot pain among Physiotherapy students.

METHODOLOGY: This co-relational study was performed in Faculty of Physiotherapy from Jan 2017 to April 2017. It includes 100 students, both male \& female from 130 volunteers using flat and heeled footwear Students having disability, obese with high BMI, Foot pain \& balance problem were excluded. They were divided into two groups. Group A includes 50 males (A1-shoes with heels, A2 shoes without heels) and Group B includes 50 females (B1-flat slippers, B2- high heeled slippers). They were assessed using the Foot Function Index and star excursion balance test to analyse effects of footwear on balance and disability. The collected data was analysed and tabulated with both inferential and descriptive statistics using SPSS version 24. Paired t-test was used to find statistical difference within the groups \& Independent t-test to find statistical difference between the groups.

RESULTS: Data suggest that foot pain is more in the Group B2 and the balance is better in Group A2. Both groups consist of students using foot wears with the heels. The $p$ value $(p<0.05)$ shows that there is a difference between the groups $A 1, A 2 \& B 1, B 2$.

CONCLUSION: This study proves that there is a significant difference in SEBT [star excursion balance test] FFI [foot function index] Score among the group A and group B. It shows that the group A2 and B2 have significantly more balance and foot pain than the group A1 and B2.

KEY WORDS: Balance, Foot Pain, High Heels, Flat Footwear, Physiotherapy

This article may be cited as: Rajalaxmi V, Lakshmi S, Kamatchi K, Jayson JC, Devika E. Correlation between High Heel Vs Flat Footwear with Balance and Foot Pain in Physiotherapy Students. J Liaquat Uni Med Health Sci. 2018;17(04):255-9. doi: 10.22442/jlumhs.181740588

\section{INTRODUCTION}

Term "BALANCE" in simple means the ability to maintain a steady and erect posture. It is used to describe dynamic posture of the body which occurs due to the internal force. And the term "POSTRUAL STABILITY" describes an individual's ability to maintain the COM (Center of Mass) without changing BOS (base of support) ${ }^{1}$. As the footwear interfere between the supporting the surface and the foot therefore it has the ability to affect balance ${ }^{2}$. Hence the features of the foot wear such as heel height and width is taken into consideration. The heel height and width of the footwear has the ability to influence gait and posture ${ }^{2}$. Anthropological evidence suggest that footwear was wore 40,000 years $\mathrm{ago}^{2}$. It has been stated that foot pain and BMI has ability to affect the posture and balance which is due to the angulations of the foot and uneven distribution of weight.

Hence the footwear, BMI, and the foot pain are considered together in this study. In order to assess the foot pain the FFI was used .The FFI is a self-reporting questionnaire developed by budimanmak, canard and roach. The foot function index is found to have good validity and reliability and has been widely used by the clinicians for the research purpose $^{3}$. FFI is composed of three subscales pain, disability and activity limitation ${ }^{4}$.

The balance is tested using SEBT. It is a dynamic test used for physically active people. It is a non instrumental test however it is more reliable ${ }^{5}$. The goal of this test is to have a stable BOS on the supporting $\operatorname{limb}$ throughout the excursion. The star pattern and the limb length measurement is being used to increase the accuracy of the test ${ }^{6}$. Gribble in 2013 showed a high level of intra-rater reliability of the star excursion balance test. Hence the study aims to examine the correlation of the habitual footwear and its role in balance and foot pain among students and also to reveal the effects of footwear on back pain and foot disorders in the later ages.

Due to the usage of improper foot wears the normal alignment of the foot is affected. It varies with heeled foot wears and the flat wears. Alignment is totally altered in flat footwear, forefoot and heel are in same alignment so weight transmission is distributed evenly, however in using heeled foot wears forefoot is 
positioned lower than the heel part which in turn produces more weight over the forefoot as well as increase in the angulations of the foot too ${ }^{7}$. The greater the height of the heels, greater the weight will be transmitted to the forefoot ${ }^{8}$. In normal foot position, weight transmitted to the forefoot is less than the hind foot.

Angulations of the foot produce considerable variations in the alignment of the other parts of the body. Awareness of our body position comes from the sense of touch and perceived motion. Unsurprisingly, Footwear limits our proprioception sense that can lead to balancing difficulties in certain occupations. More the softness of the sole of the footwear, lesser the proprioception is felt ${ }^{9}$. Balancing ailment and foot pain are most common and frequently reported issue in recent times where 4 to 5 among 10 affected persons suspected to have it due to their improper habitual foot wears. Therefore we decided to conduct this study in our setup to find out the effects of foot wears on foot pain \& balance.

\section{METHODOLOGY}

This co relational study was conducted for 04 months from Jan 2017 to April 2017 at the department of Physiotherapy, Educational \& Research Institute University, Velappanchavadi, Chennai, India after getting approval from Institutional Review Board [Ref No. 0019/PHYSIO/IRB/2016], This study was carried out among 100 Physiotherapy students. Students were selected based on convenient sampling method with the inclusion criteria includes females using flat and heeled footwear and males using shoes with and without heels. Students having foot pain with no associated disability were included Students with disability, obese with high BMI, having foot pain or disability were excluded from study. Participants were fully explained about the study including benefits of participating in the study and about the outcome measures \& written informed consent was granted. They were assured that their participation is voluntary with strict maintenance of their confidentiality \& no harms to them. They are then divided into groups. Group A includes 50 males (A1-shoes with heels, A2 shoes without heels) and Group B 50 females. (B1-flat slippers, B2- high heeled slippers). Details, the samples were assessed using the FFI and star excursion balance test (STAR pattern depends on the limb length of each individual) in order to analyze the effects of habitual footwear's on balance and disability.

\section{PROCEDURE}

Based on the eligibility criteria included subjects were divided into males and females. GROUP A1( girls using flat footwear's) and GROUP A2 (girls using heels), GROUP B1 (boys using flat shoe), GROUP B2 (boys using shoes with heels). They were assessed and tested by the foot function index questionnaire and the Star excursion balance. The SEBT is tested with the floor marked in a star pattern in all eight directions (anterior, posterior, medial, lateral, Anteriomedial, Anteriolateral, Posteriomedial, PosterioLateral) 45 degree apart from each other. Subject was asked to place one foot in the centre of the star and the other foot should reach other corners. Subjects were informed to reach as far as possible in all eight directions. Each subject was given at least 4 trials to reduce the effects of errors. Because of the significant correlation between SEBT test and leg length, so it was measured till the medial malleolus from the ASIS after doing a pelvic bridging manoeuvre in order to apply a distraction to joint. The starting direction and the supporting leg were chosen randomly. Excursion measurement was calculated as an average value taken based on 3 trials.

Blinding: Investigator who assessed the outcomes was kept blind to the subject on type of foot wear. Then statistician who analysed the outcome was also kept blind to group allocation by renaming the groups with numbers [girls, boys, flat footwear and high heel].

Data collected was analysed and tabulated for both inferential and descriptive statistics. All the parameters were assessed using statistical package for social science (SPSS) version 24. Paired t-test was used to find statistical difference within the groups \& Independent t-test (Student t-Test) was adopted to find statistical difference between the groups

\section{RESULTS}

On comparing the mean values of group $A \& B$ between $A 1$ \& $A 2$ and $B 1$ \& $B 2$, group $B 2$ \& $A 2$ showed significant increase in SEBT and FFI compared with group $A 1$ \& B1. On comparing the mean values of group A2 and B2, Group A2 showed significant increase in SEBT and decrease in FFI compared with Group B2. When comparing between A1 and A2, both foot pain and balance was considerably high in the A2 group (Table I). When comparing between B1 and B2, Group B2 showed more balance and foot pain (Table II). Data suggest that the foot pain was more severe in Group B2 and balance was better in the Group A2. These both groups were consists of students using foot wears with heels (Table III). The $p$ value $(p<0.05)$ showed that there was a significant difference between the groups A1, A2 \& B1, B2.

The above table shows Mean, Standard Deviation (S.D), Student t-test, degree of freedom (df) and p-value of the SEBT \& FFI between (Group A1) \& 
V. Rajalaxmi, S. Lakshmi, K. Kamatchi, C.J. Jayson, Devika E

TABLE I: COMPARISON OF SEBT \&FFI BETWEEN GROUP - A1 AND - A2

\begin{tabular}{|c|c|c|c|c|c|c|c|}
\hline \multirow{2}{*}{ TEST } & \multicolumn{2}{|c|}{ GROUP - A1 } & \multicolumn{2}{c|}{ GROUP - A2 } & \multirow{2}{*}{ T- TEST } & \multirow{2}{*}{ Df } & \multirow{2}{*}{ P- Value } \\
\cline { 2 - 5 } & MEAN & S.D & MEAN & S.D & & & \\
\hline SEBT & 72.60 & \pm 8.64 & 82.19 & \pm 6.22 & -.450 & 48 & $.000^{* * *}$ \\
\hline FFI & 19.12 & \pm 8.93 & 31.61 & \pm 15.24 & -3.53 & 48 & $.000^{* * *}$ \\
\hline \multicolumn{7}{|l|}{$(* * *-P \leq 0.001)$}
\end{tabular}

TABL II: COMPARISON OF SEBT \& FFI BETWEEN GROUP - B1 AND - B2

\begin{tabular}{|c|c|c|c|c|c|c|c|}
\hline \multirow{2}{*}{ TEST } & \multicolumn{2}{|c|}{ GROUP - B1 } & \multicolumn{2}{|c|}{ GROUP - B2 } & \multirow{2}{*}{$\mathrm{t}$ - TEST } & \multirow{2}{*}{ Df } & \multirow{2}{*}{ SIGNIFICANCE } \\
\hline & MEAN & S.D & MEAN & S.D & & & \\
\hline SEBT & 71.29 & 7.96 & 76.71 & 5.54 & -.279 & 48 & $.000^{* \star *}$ \\
\hline $\mathrm{FFI}$ & 21.69 & 8.82 & 36.53 & 8.10 & -6.19 & 48 & $.000^{* * *}$ \\
\hline
\end{tabular}

TABLE III: COMPARISON OF SEBT \& FFI BETWEEN GROUP - A2 AND - B2

\begin{tabular}{|c|c|c|c|c|c|c|c|}
\hline \multirow{2}{*}{ TEST } & \multicolumn{2}{|c|}{ GROUP - A2 } & \multicolumn{2}{c|}{ GROUP - B2 } & \multirow{2}{*}{ - TEST } & \multirow{2}{*}{ Df } & \multirow{2}{*}{ P - Value } \\
\cline { 2 - 6 } & MEAN & S.D & MEAN & S.D & & & \\
\hline SEBT & 82.19 & \pm 6.22 & 76.17 & \pm 5.54 & 3.28 & 48 & $.002^{* *}$ \\
\hline FFI & 31.61 & \pm 15.24 & 36.53 & \pm 8.10 & -1.425 & 48 & $.061^{* *}$ \\
\hline$\left(^{* * *}-P \leq 0.05\right)$
\end{tabular}

(Group A2).

This table shows that statistically significant difference in SEBT \& FFI between Group A1 \& A2 (***- P $\leq$ 0.001) On Comparing Mean Values of Group A1 \& A2, Group A2 Shows Increase in SEBT \& FFI compared with Group A1

The above table shows the Mean, Standard Deviation (S.D), Student t-test, degree of freedom (df) and $p$-value of the SEBT \& FFI between (Group B1) \& (Group B2)

This table shows that statistically significant difference in SEBT \& FFI between Group A1 \& A2 ${ }^{* * *}-\mathrm{P} \leq$ 0.001) On Comparing Mean Values of Group B1 \& B2, Group B2 Shows Increase in SEBT \& FFI compared with Group B1

The above table shows the Mean, Standard Deviation (S.D), Student t-test, degree of freedom (df) and p-value of the SEBT \& FFI between (Group A2) \& (Group B2)

This table shows statistically significant difference in SEBT \& FFI between Group A2 \& B2 (***- P $\leq 0.05)$ On Comparing Mean Values of Group A2 \& B2, Group A2 Shows increase in SEBT \& Decrease in FFI compared with Group B2

\section{DISCUSSION}

This study was conducted to analyse the correlation of habitual footwear with balance and foot pain among physiotherapy students. Students group has been elected in order to create awareness about the effects of using improper foot wears on later ages. In this study 100 subjects were selected with the mean age of 20 years based on the inclusion criteria and were divided into two groups Group A and Group B . All four groups had equal numbers of participants and showed significant difference in their mean values of SEBT and FFI. Analysis of the data revealed that foot pain and balance is more among the GROUP A2 and B2. When comparing the 2 groups GIRLS GROUP i.e. A1 and $\mathrm{A} 2$ both foot pain and the balance is considerably high in the $A 2$ group. When comparing the 2 groups of BOYS B1 and B2. Group B2 as more balance and foot pain. The data suggest that the foot pain is more in the GROUP B2 and the balance is better in the GROUP A2 were both the group consists of the students using foot wears with the heels. The $p$ value $(p<0.05)$ shows that there is a significant difference between the groups $A 1 A 2$ and $B 1$ B2 hence the null hypothesis is rejected.

Hence this study shows that wearing heeled \& improper footwear leads to foot pain occurrence among the students when used for prolonged duration. Wearing heeled footwear leads to pain in heal initially \& later whole foot and also leads to 
malalignment of foot structures, increased lumbo-sacral angle and imbalance of muscle power between the agonist and the antagonist which results in foot pain, back pain, abdominal weakness, decreased proprioception and impaired balance in the later years of life. This is the hidden fact behind the increased prevalence of foot pain and back pain above 40 years of age. Girls are more affected when compared to boys because of change in the alignment of foot in wearing heels and shoes.

There is an increased risk of osteoarthritis in obese women who constantly use high heels ${ }^{10}$. The head protrusion angle (HP angle) was found to be more for those who regularly use high heels than those using occasionally ${ }^{11}$. On comparison with general High Heel Shoes, revised High Heel Shoes puts more pressure on the rear foot, comparatively lesser pressure on the forefoot, and increases balance control ${ }^{12}$. High-heeled and flat wears have adverse effects on the body whereas middle-heeled $(4 \mathrm{~cm})$ shoes are harmless for women $^{13}$. Use of high heels said to alter static balance in healthy young women which also increases the oscillation of the centre of pressure, irrespective of visual restriction ${ }^{14}$. High-heeled shoes were correlated with hallux valgus and musculoskeletal pain ${ }^{15}$. Postural abnormalities including hyper lordosis in lumbar region, ante version in pelvis, valgus in knee accompanied with forward posture in head may result from using high heels. The continuous use of high heels is also prone to cause higher venous pressure in leg. Postural changes and body balance were influenced by the main factors like the height and the width of the shoes ${ }^{8}$.

Lee CM $2001^{16}$ stated that women using high heels indicate frequent complaints of LBA in later life. It's also a known fact that increasing heel heights increases the neck protrusion angle and the total body postural alignment changes leads to musculoskeletal problems. During gait cycle, the movements of the lower extremities were reduced with increase in heel height in women in 20's ${ }^{17-24}$.

The subjects in this study using heels had more foot pain than subjects using flat footwear's due to the malalignment of foot structures. The muscles surrounding the ankle get stretched and causes pain. The balance doesn't show much significant difference because initially the restriction of ROM and muscle strength is not predominant . However when heels are worn for longer periods it tends to affect the balance also.

This study recommends inclusion of subjects with bare foot in the future study, Prospective studies on wearing high heels are required to be conducted to know long term effects, inclusion of heel heights and different materials of footwear can also be included, Different age groups can also be included in these studies to assess correlation of back pain with wearing heels as they may interfere with para-spinal muscle activation, neck protrusion angle, lumbo-sacral angle and posture outcomes.

\section{CONCLUSION}

This study shows that there is significant difference in the scores of SEBT and Foot Function Index among the group $A 1$ and $A 2$ and group $B 1$ and B2.The results of the study concludes that wearing heels of any type affects the alignment of the structures of the foot and increases the lumbo sacral angle causing foot pain and impaired balance .Wearing high heels habitually for a long term should be avoided and it is necessary to be aware in selecting the footwear.

Authors Contribution: All authors have contributed equally.

Ethical Considerations: The manuscript was approved by Institutional Review board of Faculty of physiotherapy [0019/PHYSIO/IRB/2016].

Conflict of Interest: There are no financial or Non-financial Conflicts of interest among authors

Funding: This is a self-funded study. Funded by first and second author

\section{REFERENCE}

1. Donateli RA. Normal biomechanics of foot and ankle. J Orthop Sports Phys Ther 1985; 7(3):9195.

2. Barton CJ, Bonanno D, Menz HB. Development and evaluation of a tool for assessment of footwear characteristics. J Foot Ankle Res 2009; 2:10. doi: 10.1186/1757-1146-2-10.

3. Agel J, Beskin JL, Brage M, Guyton GP, Kadel NJ, Saltzman CL, et al. Reliability of the foot function index:: A report of the AOFAS outcomes committee. Foot Ankle Int 2005; 26(11): 962-7.

4. Budiman-Mak E, Conrad KJ, Roach KE. The Foot Function Index. A measure of foot pain and disability. J Clin Epidemiol 1991; 44(6): 561-7.

5. Gribble PA, Hertel J. Consideration for normalizing measures of star excursion balance test. Meas Phys Educ Exercise Sci 2009; 7(2): 89-100.

6. Bouillon L, Baker JL. Dynamic balance difference as measured by star excursion balance test between Adult Aged and Middle Aged Women. Sports Health 2011; 3(5): 466-9.

7. Chang-Min L, Eun-Hee J, Andris F. Biomechanical effect of wearing high heeled shoes. Int J Ind Ergonom 2001; 28(6): 321-26.

8. Silva AM, de Siqueira GR, da Silva GA. Implications of high heeled shoes on body posture of adolescents. Rev Paul Pediatr 2013; 31(2): 265-71. 
9. Frey C. Foot health and shoewear for women. Clin Orthop Relat Res 2000; 372:32-44.

10. Titchenal MR, Asay JL, Favre J, Andriacchi TP, Chu CR. Effects of High Heel Wear and Increased Weight on the Knee during Walking. J Orthop Res 2015; 33(3): 405-11. doi: 10.1002/jor.22775.

11. Lunes DH, Monte-Raso W, Santos CBA, Castro FA, Salgado HS. Postural influence of high heels among adult women: analysis by computerized photogrammetry. Rev Bras Fisioter 2008; 12(6): 454-59.

12. Bae $Y H$, Ko M, Park YS, Lee SM. Effect of revised high-heeled shoes on foot pressure and static balance during standing. J Phys Ther Sci 2015; 27(4):1129-1131.

13. Ko DY, Lee HS. The Changes of COP and Foot Pressure after One Hour's Walking Wearing Highheeled and Flat Shoes. J Phys Ther Sci 2013; 25 (10):1309-12

14. Gerber SB, Costa RV, Grecco LAC, Pasini H, Marconi NF, Oliveira CS. Interference of highheeled shoes in static balance among young women. Hum Mov Sci 2012; 31(5):1247-52. doi: 10.1016/j.humov.2012.02.005.

15. Barnish MS, Barnish J. High-heeled shoes and musculoskeletal injuries: a narrative systematic review. BMJ Open 2016; 6(1):e010053. doi: 10.1136/bmjopen-2015-010053.

16. Lee CM, Jeong EH, Freivalds A. Biomechanical effect of wearing high heeled shoes. Int $\mathrm{J}$ of Ind Ergonom 2001; 28(6); 321-326.

17. Karimi N, Moedi SE, Rahnama L, Arsalan SA, Nia SA. Assessment of the High-Heel Shoes Effect on
Head Protrusion Angle. Phys Treatments 2017; 6 (2):109-113.

18. Lee CR. The Effects of Lower Extremity Angle According to Heel-height Changes in Young Ladies in their 20s during Gait. J Phys Ther Sci 2014; 26(7):1055-58.

19. Mika A, Oleksy L, Kielnar R, Świerczek M. The influence of high heels and low heeled shoes on balance in young women. Acta Bioeng Biomech 2016; 18(3):97-103.

20. Simonsen EB, Svendsen $M B$, Nørreslet $A$, Baldvinsson HK, Heilskov-Hansen T, Larsen PK, et al. Walking on high heels changes muscle activity and the dynamics of human walking significantly. J Appl Biomech 2012; 28(1): 20-28

21. Han D. Muscle activation of paraspinal muscles in different types of high heels during standing. J Phys Ther Sci 2015; 27(1):67-69.

22. Tedeschi Filho W, Dezzotti NR, Joviliano EE, Moriya $T$, Piccinato $C E$. Influence of high heeled shoes on venous function in young women. J Vasc Surg 2012; 56(4):1039-44. doi: 10.1016/ j.jvs.2012.01.039.

23. Teixeira CE, Retondar JJ. The use of high heel by young women: the biomechanics of movement and the imaginary of elegancy. Rev Corpus Scient $2011 ; 7: 38-54$.

24. Mika A, Oleksy L, Mika P, Marchewka A, Clark $B C$. The effect of walking in high and low heeled shoes on erector spinae activity and pelvis kinematics during gait. Am J Phys Med Rehabil 2012; 91(5):425-34.

doi: 10.1097/PHM.0b013e3182465e57.
AUTHOR AFFILIATION:

V. Rajalaxmi (Corresponding Author)

Faculty of Physiotherapy

Dr. M.G.R. Educational \& Research Institute University

Velappanchavadi, Chennai - 600 077, Tamil Nadu, India.

Email: rajalaxmi.physio@drmgrdu.ac.in

\section{S. Lakshmi}

BPT Internee

Dr. M.G.R. Educational \& Research Institute University

Velappanchavadi, Chennai - 600 077, Tamil Nadu, India.

\section{K. Kamatchi}

Assistant Professor, Faculty of Physiotherapy

Dr. M.G.R. Educational \& Research Institute University

Velappanchavadi, Chennai - 600 077, Tamil Nadu, India.

C.J. Jayson

Assistant Professor, Faculty of Physiotherapy

Dr. M.G.R. Educational \& Research Institute University

Velappanchavadi, Chennai - 600 077, Tamil Nadu, India.

Devika E

Assistant Professor, Faculty of Nursing

Dr. M.G.R. Educational \& Research Institute University Velappanchavadi, Chennai - 600 077, Tamil Nadu, India. 